\title{
Effect of Chronic Supplementation of Branched Chain Amino Acids on Exercise-Induced Muscle Damage in Trained Athletes
}

\author{
Shweta Shenoy, Mrinal Dhawan and Jaspal Singh Sandhu \\ Department of Sports Medicine \& Physiotherapy, Guru Nanak Dev University, Amritsar 143005 Punjab, India
}

\begin{abstract}
PURPOSE: Branched Chain Amino Acids (BCAA) has been considered an important nutritional strategy to improve skeletal muscle protein turnover in many conditions especially following exercise induced muscle damage. Exercise induced muscle damage (EIMD), a phenomenon impairs muscle function and hampers athletic performance. The effects of consumption of BCAA for a chronic period ( 4 weeks) on EIMD in trained athletic population have never been explored. Therefore, the aim of the present study was to examine the effects of chronic consumption (4 weeks) of BCAA on indices of muscle damage elicited via a bout of damaging exercise in trained athletes. METHODS: Twenty trained males (20 road cyclists) aged 18-28 years were randomly assigned to two groups (BCAA and Placebo) $(n=10)$. The damaging exercise consisted of 100 consecutive drop-jumps. Biochemical markers including creatine kinase (CK), high sensitivity c reactive protein (hs-cRP) and myeloperoxidase (MPO), isometric knee muscle strength, muscle soreness, aerobic capacity $\left(\mathrm{VO}_{2 \max }\right)$ and heart rate $(\mathrm{HR})$ were measured. RESULTS: Differences were observed in pre-and post-supplementation periods among all the participants with mean height and weight values of $168.57(4.5) \mathrm{cm}$ and 61.74 (4.55) $\mathrm{kg}$ respectively as calculated by the anthropologist randomly allocated to the two groups in all tested parameters indicating the effectiveness of BCAA in attenuating muscle damage and enhancing muscle recovery with chronic consumption when compared to placebo, however in contrast to our expectations based on symptoms and our clinical judgment during the study statistically significant difference $(P<0.05)$ were noticed with biochemical indices only. CONCLUSION: Our findings suggest that chronic BCAA supplementation proved to be an effective meansof reducing muscle damage, enhancing muscle protein synthesis and recovery following EIMD as compared to placebo in well trained athletic population.
\end{abstract}

Key words: Amino acids, branched-chain, exercise, creatine kinase, C-reactive protein, muscle damage.

\section{Introduction}

Adequate evidence in literature [1-3] have concluded that supplementation with amino acids following exercise led to more rapid recovery from muscle fatigue and reduces exercise induced proteolysis, muscle soreness and plasma CK activity. Exercise Induced Muscle Damage (EIMD) is a well-known phenomenon in exercise literature follows unaccustomed eccentric activities $[4,5]$ like plyometric, long distance running and resistance activities [6-14]. Eccentric exercise-induced muscle damage is indicated by prolonged decreases in muscle strength range of motion (ROM), swelling, delayed onset muscle

Corresponding Author: Dr. Shweta Shenoy, Associate Professor, research field: exercise physiology. soreness (DOMS), increased muscle proteins, $\mathrm{CK}$ in the blood [15]. The impairment of muscle function caused by damage reduces performance and prevents the athlete to employ him/herself in high intensity exercises on consequent days [16]. Thus, recovery from such activities become an integral part of training regimen. Branched-chain amino acids (BCAAs), due to their relative abundance in skeletal muscle are being the centre of attraction [17-19]. According to Breen et al. [20], BCAA are essential amino acids that are key substrates for protein synthesis and recovery, and have shown to lessen the effects of EIMD effectively following strenuous endurance exercise. Furthermore, BCAA helped conserving muscle mass in settings of protein loss. A study conducted by Nosaka et al. [21] 
documented that amino acid supplementation containing around 60\% BCAA significantly reduced muscle damage and soreness when consumed before and during the recovery period following a damaging bout of eccentric contractions. Similarly, studies have examined that recovery from heavy endurance activities have also shown the benefits of BCAA in reducing muscle damage and accelerating muscle recovery [22-24]. To support the findings of the above studies, Greer et al. [18] by means of a cycling protocol also demonstrated that acute ingestion of $50 \mathrm{~g}$ of BCAA led to decrease in the circulating CK levels when measured at 4,24 , and $48 \mathrm{~h}$ post exercise, reduction in the level of delayed-onset muscle soreness (DOMS) experienced $24 \mathrm{~h}$ post-exercise and also attenuated the decrease in leg-flexion torque $48 \mathrm{~h}$ post exercise. Nevertheless, current evidence is promising about the positive effects of BCAA on recovery indices following damaging muscle exercises.

Though, the current evidence regarding the effects of acute supplementation with BCAA on EIMD is encouraging, the effects of consuming BCAA supplements for a chronic duration of more than two weeks have never been investigated.

Hence, there is a lacuna in exercise literature exploring the role of BCAA supplementation for a chronic duration on muscle protein synthesis and recovery following EIMD in trained athletic population.

Therefore, the aim of our study was to examine the efficacy of chronic (4 weeks) supplementation of BCAA on recovery from a single damaging bout of exercise in trained athletes. We specifically focused on biochemical markers including muscle damage, creatine kinase (CK), inflammation, high sensitivity c reactive protein (hs-cRP) and oxidative stress, myeloperoxidase (MPO) besides other indices of muscle performance and aerobic function.

\section{Materials and Methods}

\subsection{Participants}

Twenty trained road cyclists volunteered and gave their written informed consent to participate in this study [16]. Participants were mean 20.03 (1.19) years of age, 168.57 (4.5) cm tall and weighed 61.74 (4.55) $\mathrm{kg}$. All participants who engaged themselves in specific, regular training of $30 \mathrm{~h}$ a week during the competitive season were included in the study. Participants who were consuming any dietary supplements in the past one month were excluded from the study. Ten participants were randomly and evenly allocated in a stratified, double blinded manner among two groups-BCAA and Placebo. All the other investigators, study personnel, and subjects were blinded to the type of supplement used by the two groups during the study. Ethical approval to conduct the study was granted by institutional ethical committee, Faculty of Sports Medicine and Physiotherapy, Guru Nanak Dev University, Amritsar.

\subsection{Experimental Design}

The experimental protocol followed a randomized, double blind, placebo controlled design [16]. The research was based on four weeks supplementation program including the pre, post and during supplementation period. In the pre- and post-supplementation period, the subjects were called and their baseline readings (Blood, Strength, Muscle Soreness, HR Response and $\mathrm{VO}_{2 \max }$ ) were determined. Followed by this, the players were called again to perform the Muscle Damaging Exercises and no readings were taken. The criterion variables hs-cRP, $\mathrm{CK}, \mathrm{MPO}$, isometric knee muscle strength, maximum aerobic capacity $\left(\mathrm{VO}_{2 \max }\right)$, heart rate (HR) and Muscle soreness (intensity indicated as perceived pain on a VAS scale) were obtained at $24 \mathrm{~h}$ and $48 \mathrm{~h}$ post EIMD. In the supplementation period, the players were segregated into two groups (10 in each) and they were provided BCAA and placebo for four weeks. During this period, the players were on relative rest and on maintenance warm up exercises. No hard training schedule was on in this period. 


\section{Exercise-Induced Muscle Damage in Trained Athletes}

\subsection{Exercise Protocol}

Participants have performed a total of 100 drop-jumps from a height of $0.6 \mathrm{~m}$. On landing, participants were encouraged to immediately jump vertically with maximal force. Five sets of 20 drop-jumps were performed with a $10 \mathrm{sec}$ interval between each jump and the rest of 2 min between each set was given. This protocol has been previously shown to cause significant elevations in muscle damage indices $[16,21,25]$.

\subsubsection{Biochemical Indices}

Blood was drawn into heparin tubes, from the median cubital vein in the antecubital space of the forearm and was spun at $3000 \times \mathrm{g}$ and the plasma was stored at $-70^{\circ} \mathrm{C}$ until analysis [26]. Plasma was analyzed for CK and hs-cRP using assay kits from DiaSys Diagnostic Systems GmbH. (Holzeim, Germany). Plasma MPO was analyzed using ELISA kit from BioVendor, Research and Diagnostic Products. (Brno, Czech Republic).

\subsubsection{Isometric Peak Torque Assessment}

Isometric peak torque was assessed of both the quadriceps (extension) and the hamstrings (flexion) at the knee joint of both the limbs using HUR 5340 leg extension/curl, a computer controlled isoinertial dynamometer [27] following a warm up session.

\subsubsection{Maximum Aerobic Capacity $\left(\mathrm{VO}_{2 \max }\right)$} Assessment

$\mathrm{VO}_{2 \max }$ was assessed using an open circuit breath by breath automated precalibrated portable gas analyzer MetaMax 3B (Cortex, Germany) integrated with a motorized treadmill $\mathrm{h} / \mathrm{p} / \mathrm{cosmos}$ mercury [cos 10198-01] (Germany). Prior to commencing the test, each participant was told about the incremental exercise test protocol, and continuous electronic heart rate monitoring was done throughout the test. Participants performed an incremental test to volitional exhaustion in accordance with the Bruce protocol [28]. $\mathrm{VO}_{2 \max }$ was determined based on a plateau in $\mathrm{VO}_{2}$ consumption or participant reaching volitional fatigue [29].

\subsubsection{Muscle Soreness}

Participants performed and held a squat $\left(90^{\circ}\right.$ knee angle) whilst, they rated their perceived muscle soreness on a $0-10 \mathrm{cms}$ VAS scale where 0 indicated no pain and 10 indicating severe pain [30].

All participants were familiarized with the testing protocol and the study was carried in between the months of August 2013 to July 2014 at Human Performance Lab, Department of Sports Medicine and Physiotherapy, Guru Nanak Dev University, Amritsar. All testing sessions were performed in morning in a climatically-controlled laboratory under similar environmental conditions (temperature, $19.3^{\circ} \mathrm{C}$ to $21.4^{\circ} \mathrm{C}$; relative air humidity, $30 \%$ to $32 \%$ ) [31]. Participants were injury free and were off training (only maintaining a basic minimum of physical activity to prevent deconditioning) during the supplementation period, maintained regular dietary habits and avoid taking additional proteins and nutritional supplements [16].

\subsection{Supplementation Protocol}

Participants ingested 10 grams, twice a day either of BCAA or placebo (aspartame based artificial sweetener) mixed with $\sim 300 \mathrm{ml}$ of water for 4 weeks [16]. The BCAA supplement (INSTANTIZED BCAA 5000 Powder Unflavored, OPTIMUM NUTRITION, Aurora, IL) contained a ratio of 2:1:1 leucine, isoleucine and valine respectively. Artificial sweetener rather than a carbohydrate-based placebo was used to prevent arise in insulin that may have altered protein metabolism [32]. Before ingestion, supplement was tested for banned substances at National Dope Testing Laboratory, New Delhi. The dosage of BCAA was based on the manufacturer's recommendations and previous supplementation research $[17,30]$.

\section{Results and Discussion}

All biochemical indices used in depicting muscle damage including hs-cRP, CK and MPO demonstrated a trend in favor of less muscle damage and enhanced 
muscle recovery with time following supplementation with BCAA when compared to placebo.

The data shown in the Table 1 were the mean values of the baseline data (Day 1), post 24 hours (Day 2) and post 48 hours (Day 3) in both pre and post supplementation period. Furthermore, explanation on the data depicted is in Table 2. It was revealed that in both pre and post supplementation periods, an increase was observed in the mean values from Day 1 to Day 2 in both groups, however in the post supplementation period the degree of change of mean values between Day $1 \&$ Day 2 were found to be lower than the degree of change of the pre supplementation mean values in the BCAA group and were also statistically significant depicting less muscle damage recorded at $24 \mathrm{~h}$ post damaging exercises in the group who had consumed BCAA compared to placebo. Furthermore, it was found that mean values dropped with due course of time (from $24 \mathrm{~h}$ to $48 \mathrm{~h}$ ) following damaging exercises depicting a phase of muscle recovery both before and after supplementation of either BCAA or placebo but the degree of change being greater following BCAA supplementation suggestive of the effectiveness of the supplement in enhancing muscle recovery when compared to placebo. The present findings correspond to previous observations [16] pointing towards limiting muscle damage and thereby enhancing recovery by branched chained amino acids as the main mechanism. However, we cannot support this postulate as it seems reasonable to state that greater bioavailability of essential amino acids could have maintained cell membrane integrity thereby decreasing secondary muscle damage [16].

Compared with research into the response of muscle damage markers like creatine kinase (CK) following chronic/long term supplementation with BCAA after a damaging exercise bout less is known concerning response of inflammatory and oxidative stress markers like hs-cRP and MPO respectively and to our knowledge this is the first study to illustrate quantitative changes in the levels of MPO in due course of time in the current settings. Our present study backs the evidence provided by Atashak et al. [33] showing anti-inflammatory properties of BCAA as suggested with significant greater degrees of changes in the mean value in our supplemented group. Taking into account our previous observations regarding antioxidant activity of amino acids on tissue oxidative stress in human intestinal epithelial cell model [34], the present findings suggests similar biochemical mechanisms active in the background responsible for attenuating exercise induced muscle damage.

Mean values of isometric peak torque at the knee joint (both extension and flexion), measured for right and left limb showed a decrease at Day 2, i.e. 24 hours post damaging exercises in both the groups before and after supplementation. There is a less degree of change (decrease) of the post supplementation mean values of the BCAA group as compared to the placebo group signifying the effectiveness of the experimental supplement in attenuating the reduction of muscle force following damaging exercises. These findings suggest a possibility of improved regulation of muscle protein metabolism following supplementation post EIMD [35, 36]. Moreover, we observed an improvement in the mean values of muscle force in the subsequent day of recovery (transition from Day 2 to Day 3 values) both before and after supplementation of either BCAA or placebo, yet contrary to our hypothesis BCAA convincingly enhanced recovery after supplementation only during flexion movement of both knees as depicted by a greater degree of change in the mean values between Day 2 \& Day 3 when compared to placebo.

$\mathrm{VO}_{2 \max }$ assessment showed a trend of improved response to BCAA supplementation as compared to placebo. Degree of change of mean values between Day $1 \&$ Day 2 in the post supplementation period was found to be lower than degree of change of mean values in the pre supplementation period in the group consuming BCAA, likewise the degree of change of mean values between Day $2 \&$ Day 3 in the post 
Table 1 Descriptive statistics (Mean \pm SD values) of all criterion variables before and after supplementation in cyclists.

\begin{tabular}{|c|c|c|c|c|c|c|c|c|}
\hline \multirow{3}{*}{ No } & \multirow{3}{*}{ Criterion Variables } & \multirow{3}{*}{ Groups } & \multicolumn{3}{|c|}{ Pre-Supplementation Data } & \multicolumn{3}{|c|}{ Post-Supplementation Data } \\
\hline & & & Baseline Data & After $24 \mathrm{~h}$ & After $48 \mathrm{~h}$ & Baseline Data & After $24 \mathrm{~h}$ & After $48 \mathrm{~h}$ \\
\hline & & & $($ Mean \pm SD) (Day 1) & $($ Mean \pm SD) $($ Day 2$)$ & $($ Mean \pm SD) (Day 3) & $($ Mean \pm SD) $($ Day 1$)$ & $($ Mean \pm SD) (Day 2) & $($ Mean \pm SD) (Day 3) \\
\hline \multirow{2}{*}{1} & \multirow{2}{*}{ hs-cRP (mg/dl) } & BCAA & $3.85 \pm 0.7$ & $7.23 \pm 1.6$ & $6.07 \pm 1.6$ & $2.6 \pm 0.7$ & $5.16 \pm 1.1$ & $3.41 \pm 0.7$ \\
\hline & & Placebo & $3.94 \pm 0.5$ & $9.29 \pm 1.1$ & $7.79 \pm 1.3$ & $3.93 \pm 0.6$ & $9.30 \pm 1.1$ & $7.81 \pm 1.3$ \\
\hline \multirow{2}{*}{2} & \multirow{2}{*}{ CK (IU/L) } & BCAA & $143.72 \pm 10.4$ & $470.65 \pm 45.9$ & $421.40 \pm 57.8$ & $62.33 \pm 10.4$ & $264.73 \pm 19.3$ & $170.74 \pm 10.6$ \\
\hline & & Placebo & $140.8 \pm 10.8$ & $382.21 \pm 37.6$ & $335.57 \pm 36.7$ & $139.77 \pm 10.4$ & $382.75 \pm 35.9$ & $337.03 \pm 36.9$ \\
\hline \multirow{2}{*}{3} & \multirow{2}{*}{ MPO (ng/L) } & BCAA & $8.18 \pm 1.5$ & $12.27 \pm 2.3$ & $10.95 \pm 2.3$ & $6.04 \pm 1.5$ & $9.07 \pm 1.6$ & $7.67 \pm 1.3$ \\
\hline & & Placebo & $8.39 \pm 0.9$ & $13.43 \pm 2.0$ & $11.56 \pm 1.8$ & $8.37 \pm 0.9$ & $13.44 \pm 2.0$ & $11.56 \pm 1.7$ \\
\hline \multirow{2}{*}{4} & \multirow{2}{*}{ ISOR EXT (Nm) } & BCAA & $199.80 \pm 12.9$ & $170.40 \pm 12.9$ & $183.40 \pm 11.9$ & $225.3 \pm 9.6$ & $196.1 \pm 11.7$ & $215.2 \pm 10.7$ \\
\hline & & Placebo & $194.60 \pm 17.1$ & $172.40 \pm 17.5$ & $183.70 \pm 17.4$ & $194.7 \pm 16.5$ & $169.8 \pm 14.9$ & $184 \pm 18.2$ \\
\hline \multirow{2}{*}{5} & \multirow{2}{*}{ ISOR FLEX (Nm) } & BCAA & $98.9 \pm 7.6$ & $72.70 \pm 9.1$ & $83.70 \pm 9.2$ & $117.9 \pm 5.9$ & $92.6 \pm 7.1$ & $107.9 \pm 6.7$ \\
\hline & & Placebo & $92.50 \pm 8.9$ & $74.90 \pm 7.6$ & $86.20 \pm 6.9$ & $91.8 \pm 10.2$ & $75.3 \pm 6.4$ & $85.6 \pm 7.2$ \\
\hline \multirow{2}{*}{6} & \multirow{2}{*}{ ISOL EXT (Nm) } & BCAA & $178.80 \pm 9.5$ & $152.70 \pm 13.3$ & $161.50 \pm 10.3$ & $200.9 \pm 10.8$ & $178.4 \pm 9.3$ & $189.3 \pm 8.3$ \\
\hline & & Placebo & $178.50 \pm 10.1$ & $157.90 \pm 9.9$ & $172.10 \pm 9.6$ & $179.7 \pm 9.6$ & $156.2 \pm 7.9$ & $171.9 \pm 10.4$ \\
\hline \multirow{2}{*}{7} & \multirow{2}{*}{ ISOL FLEX (Nm) } & BCAA & $85.30 \pm 10.8$ & $62.90 \pm 12.3$ & $66.60 \pm 8.6$ & $104.1 \pm 10.8$ & $82.4 \pm 11.2$ & $97.8 \pm 19.4$ \\
\hline & & Placebo & $80.10 \pm 6.9$ & $66.30 \pm 7.9$ & $82.00 \pm 8.3$ & $80.3 \pm 19.8$ & $66.5 \pm 8.8$ & $81.5 \pm 8.3$ \\
\hline \multirow{2}{*}{8} & \multirow{2}{*}{$\begin{array}{l}\mathrm{VO}_{2 \max } \\
(\mathrm{ml} / \text { kgmin-1) }\end{array}$} & BCAA & $57.70 \pm 4.0$ & $55.4 \pm 4.1$ & $56.3 \pm 2.7$ & $59.9 \pm 4.1$ & $58 \pm 4.2$ & $59.8 \pm 4.1$ \\
\hline & & Placebo & $56.60 \pm 4.1$ & $54.4 \pm 4.4$ & $55.60 \pm 4.2$ & $56.8 \pm 4.3$ & $54.4 \pm 4.6$ & $55.1 \pm 4.8$ \\
\hline \multirow{2}{*}{9} & \multirow{2}{*}{ HR (beats/min) } & BCAA & $175.90 \pm 12.4$ & $190.70 \pm 12.4$ & $184.8 \pm 10.9$ & $160.9 \pm 12.7$ & $175.70 \pm 12.1$ & $166.5 \pm 22.0$ \\
\hline & & Placebo & $175.00 \pm 8.3$ & $193.6 \pm 6.0$ & $184.60 \pm 4.6$ & $175 \pm 7.5$ & $193.80 \pm 6.2$ & $182.00 \pm 7.4$ \\
\hline \multirow{2}{*}{10} & \multirow{2}{*}{ VAS } & BCAA & - & $5.80 \pm 1.2$ & $4.70 \pm 1.5$ & - & $4.2 \pm 1.3$ & $2.8 \pm 1.2$ \\
\hline & & Placebo & - & $8.20 \pm 0.8$ & $7.30 \pm 0.8$ & - & $8.00 \pm 1.2$ & $7.2 \pm 1.0$ \\
\hline
\end{tabular}


Table 2 Degree of changes in between days (pre-post Supplementation values) in cyclists.

\begin{tabular}{|c|c|c|c|c|c|c|c|c|c|c|}
\hline No. & $\begin{array}{l}\text { Criterion } \\
\text { Variables }\end{array}$ & Groups & $\begin{array}{l}\text { Pre-Supp. } \\
\text { Change in Day } 1 \& 2\end{array}$ & $\begin{array}{l}\text { Post Supp. } \\
\text { Change in Day1 \&2 }\end{array}$ & - Diff. $_{1 \& 2}(95 \%$ CI $)$ & $P_{1 \& 2^{-v a l u e}}$ & $\begin{array}{l}\text { Pre-Supp. } \\
\text { Change in Day } 2 \& 3\end{array}$ & $\begin{array}{l}\text { Post Supp. } \\
\text { Change in Day } 2 \& 3\end{array}$ & - Diff. $_{2 \& 3}(95 \%$ CI $)$ & $P_{2 \& 3^{-v a l u e}}$ \\
\hline \multirow{2}{*}{1} & \multirow{2}{*}{$\begin{array}{l}\text { hs-cRP } \\
(\mathrm{mg} / \mathrm{dl})\end{array}$} & BCAA & $3.38 \pm 1.1$ & $2.56 \pm 0.7$ & $\begin{array}{l}0.81 \pm 0.7 \\
(0.31 .3)\end{array}$ & $<0.01$ & $1.16 \pm 0.3$ & $1.75 \pm 0.6$ & $\begin{array}{l}-0.58 \pm 0.6 \\
(0.11 .0)\end{array}$ & 0.01 \\
\hline & & Placebo & $5.35 \pm 0.7$ & $5.37 \pm 0.7$ & $\begin{array}{l}-0.01 \pm 0.07 \\
(0.030 .07) \\
\end{array}$ & 0.47 & $1.50 \pm 0.8$ & $1.49 \pm 0.8$ & $\begin{array}{l}0.01 \pm 0.06 \\
(0.030 .05)\end{array}$ & 0.71 \\
\hline \multirow{2}{*}{2} & \multirow{2}{*}{ CK (IU/L) } & BCAA & $326.93 \pm 42.2$ & $202.4 \pm 22.2$ & $\begin{array}{l}124.53 \pm 38.3 \\
(97.1151 .9)\end{array}$ & $<0.001$ & $49.25 \pm 13.5$ & $93.99 \pm 25.5$ & $\begin{array}{l}-44.73 \pm 28.8 \\
(24.165 .3)\end{array}$ & $<0.001$ \\
\hline & & Placebo & $241.41 \pm 35.7$ & $242.98 \pm 31.6$ & $\begin{array}{l}-1.56 \pm 7.1 \\
(3.46 .6)\end{array}$ & 0.49 & $46.64 \pm 21.8$ & $45.72 \pm 22.1$ & $\begin{array}{l}0.92 \pm 4.9 \\
(2.54 .4)\end{array}$ & 0.56 \\
\hline \multirow{2}{*}{3} & \multirow{2}{*}{ MPO (ng/L) } & BCAA & $4.09 \pm 1.5$ & $3.02 \pm 0.7$ & $\begin{array}{l}1.08 \pm 1.4 \\
(0.092 .0)\end{array}$ & $<0.05$ & $1.32 \pm 0.5$ & $1.39 \pm 0.9$ & $\begin{array}{l}-0.07 \pm 0.7 \\
(0.40 .5)\end{array}$ & 0.77 \\
\hline & & Placebo & $5.04 \pm 1.4$ & $5.07 \pm 1.4$ & $\begin{array}{l}-0.03 \pm 0.04 \\
(0.00 .06)\end{array}$ & 0.05 & $1.87 \pm 0.5$ & $1.88 \pm 0.5$ & $\begin{array}{l}-0.01 \pm 0.07 \\
(0.040 .05) \\
\end{array}$ & 0.79 \\
\hline \multirow{2}{*}{4} & \multirow{2}{*}{$\begin{array}{l}\text { ISOR EXT } \\
(\mathrm{Nm})\end{array}$} & BCAA & $29.4 \pm 6.0$ & $29.2 \pm 5.3$ & $\begin{array}{l}0.2 \pm 5.6 \\
(3.84 .2)\end{array}$ & 0.91 & $13 \pm 4.1$ & $19.1 \pm 4.8$ & $\begin{array}{l}-6.1 \pm 7.7 \\
(0.511 .7)\end{array}$ & $<0.05$ \\
\hline & & Placebo & $22.2 \pm 6.0$ & $24.9 \pm 6.9$ & $\begin{array}{r}-2.7 \pm 9.6 \\
(4.29 .6) \\
\end{array}$ & 0.39 & $11.3 \pm 2.7$ & $14.2 \pm 10.7$ & $\begin{array}{l}-2.9 \pm 9.1 \\
(3.69 .4)\end{array}$ & 0.34 \\
\hline \multirow{2}{*}{5} & \multirow{2}{*}{$\begin{array}{l}\text { ISOR FLEX } \\
(\mathrm{Nm})\end{array}$} & BCAA & $26.2 \pm 3.5$ & $25.3 \pm 3.8$ & $\begin{array}{l}0.9 \pm 4.2 \\
(2.13 .8)\end{array}$ & 0.51 & $11.0 \pm 3.2$ & $15.3 \pm 4.8$ & $\begin{array}{l}-4.3 \pm 5.9 \\
(0.18 .4)\end{array}$ & $<0.05$ \\
\hline & & Placebo & $17.6 \pm 4.9$ & $16.5 \pm 7.2$ & $\begin{array}{l}1.1 \pm 3.8 \\
(1.63 .8)\end{array}$ & 0.38 & $11.3 \pm 3.0$ & $10.3 \pm 4.2$ & $\begin{array}{l}1.0 \pm 2.1 \\
(0.52 .5)\end{array}$ & 0.16 \\
\hline \multirow{2}{*}{6} & \multirow{2}{*}{$\begin{array}{l}\text { ISOL EXT } \\
(\mathrm{Nm})\end{array}$} & BCAA & $26.1 \pm 5.6$ & $22.5 \pm 4.1$ & $\begin{array}{l}3.6 \pm 7.5 \\
(1.78 .9)\end{array}$ & 0.16 & $8.8 \pm 9.7$ & $10.9 \pm 4.9$ & $\begin{array}{l}-2.1 \pm 10.8 \\
(5.69 .8)\end{array}$ & 0.55 \\
\hline & & Placebo & $20.6 \pm 4.6$ & $23.5 \pm 6.8$ & $\begin{array}{l}-2.9 \pm 5.7 \\
(1.26 .9) \\
\end{array}$ & 0.14 & $14.2 \pm 1.9$ & $15.7 \pm 6.7$ & $\begin{array}{l}-1.5 \pm 7.1 \\
(3.66 .6) \\
\end{array}$ & 0.52 \\
\hline \multirow{2}{*}{7} & \multirow{2}{*}{$\begin{array}{l}\text { ISOL FLEX } \\
(\mathrm{Nm})\end{array}$} & BCAA & $22.4 \pm 4.3$ & $21.7 \pm 3.4$ & $\begin{array}{l}0.7 \pm 5.3 \\
(3.14 .5)\end{array}$ & 0.68 & $3.7 \pm 11.8$ & $15.4 \pm 11.0$ & $\begin{array}{l}-11.7 \pm 22.5 \\
(-4.427 .9)\end{array}$ & 0.13 \\
\hline & & Placebo & $13.8 \pm 4.3$ & $13.8 \pm 16.4$ & $\begin{array}{l}0.0 \pm 16.2 \\
(-11.511 .5)\end{array}$ & 1 & $15.7 \pm 3.6$ & $15.0 \pm 6$ & $\begin{array}{l}-0.7 \pm 4.9 \\
(3.43 .6)\end{array}$ & $<0.001$ \\
\hline \multirow{2}{*}{8} & \multirow{2}{*}{$\begin{array}{l}\mathrm{VO}_{2 \max } \\
(\mathrm{ml} / \text { kgmin-1) }\end{array}$} & BCAA & $2.3 \pm 0.5$ & $1.9 \pm 0.7$ & $\begin{array}{l}0.4 \pm 0.9 \\
(0.31 .1)\end{array}$ & 0.22 & $0.9 \pm 2.6$ & $1.8 \pm 2.1$ & $\begin{array}{l}-0.9 \pm 2.7 \\
(-1.12 .8)\end{array}$ & 0.32 \\
\hline & & Placebo & $2.2 \pm 0.8$ & $2.4 \pm 0.5$ & $\begin{array}{l}-0.2 \pm 0.91 \\
(0.40 .8)\end{array}$ & 0.5 & $1.2 \pm 0.42$ & $0.7 \pm 1.1$ & $\begin{array}{l}0.5 \pm 1.2 \\
(0.41 .4)\end{array}$ & 0.24 \\
\hline \multirow{2}{*}{9} & \multirow{2}{*}{$\begin{array}{l}\text { HR } \\
\text { (beats/min) }\end{array}$} & BCAA & $14.8 \pm 4.3$ & $14.8 \pm 4.3$ & $\begin{array}{l}0 \pm 3.8 \\
(2.72 .7)\end{array}$ & 1 & $5.9 \pm 3.6$ & $9.2 \pm 19.0$ & $\begin{array}{l}-3.3 \pm 17.8 \\
(1.15 .5)\end{array}$ & 0.57 \\
\hline & & Placebo & $18.6 \pm 3.6$ & $18.8 \pm 4.5$ & $\begin{array}{l}-0.2 \pm 2.7 \\
(1.82 .2)\end{array}$ & 0.82 & $9.0 \pm 4.4$ & $11.8 \pm 4.7$ & $\begin{array}{l}-2.8 \pm 6.0 \\
(1.57 .1) \\
\end{array}$ & 0.17 \\
\hline \multirow{2}{*}{10} & \multirow{2}{*}{ VAS } & BCAA & - & - & - & - & $1.1 \pm 0.73$ & $1.4 \pm 0.51$ & $\begin{array}{l}-0.3 \pm 0.67 \\
(0.20 .8)\end{array}$ & 0.19 \\
\hline & & Placebo & - & - & - & - & $0.9 \pm 0.56$ & $0.8 \pm 0.63$ & $\begin{array}{l}0.1 \pm 0.87 \\
(0.50 .7)\end{array}$ & 0.72 \\
\hline
\end{tabular}


supplementation period was found to be higher than in the pre supplementation period in the BCAA group, both depicting an improved lactate threshold [23] and an augmented ventilatory response [37] post EIMD due to less muscle damage and enhanced muscle recovery following supplement consumption.

HR response showed an erratic trend over time with supplement consumption. Degree of change of mean readings between Day 1 \& Day 2 in BCAA group in the post supplementation period was similar to the change of mean readings in the pre-supplementation period depicting no effect of BCAA supplementation on HR response at $24 \mathrm{~h}$ post damaging exercises compared to placebo. Correspondingly, with further readings (degree of change of mean values between Day $2 \&$ Day 3), both BCAA and placebo group showed a non-significant greater degree of mean values representing no response by the supplement.

The process of muscle soreness has been attributed to the establishment of an acute inflammatory response resulting from metabolic, mechanical and oxidative stress [38]. Muscle soreness (as depicted by perceived pain on a VAS scale) peaked at $24 \mathrm{~h}$ followed by a drop at $48 \mathrm{~h}$ post damaging exercises in both the groups. Nonetheless, we observed a greater degree of change of the mean values between Day $2 \&$ Day 3 in the post supplementation period in the group who had consumed BCAA as compared to placebo showing an additional amount of decrease in muscle soreness with BCAA consumption than placebo. Considering our previous observations $[16,19,22,39]$ and our present study, collectively attributes the above findings to the property of BCAA of facilitating protein uptake necessary for use as an energy source $[40,41]$ and as an antioxidant [34].

\section{Conclusion}

In conclusion, corresponding to findings of previous clinical trials conducted over an acute time setting, our findings suggest that BCAA supplementation over a chronic/long term time period too is effective in reducing muscle damage, enhancing muscle protein synthesis and recovery following EIMD. However, it is important to note that the extent/degree of benefit provided by long term supplementation with BCAA was not focused on when compared to supplementation in an acute time setting thereby comparing benefits of supplementation over acute time period to supplementation over chronic time periods may form a question for future research. In addition, future research could also assist in understanding the differences in the response of muscles to damage and recovery with different doses and time duration of BCAA supplementation, in order to establish baseline dosages of BCAA required for attenuating muscle damage and enhancing recovery following an acute bout of specific muscle damaging exercises in well trained athletes.

\section{References}

[1] Ohtani, M., Sugita, M., and Maruyama, K. 2006. "Amino Acid Mixture Improves Training Efficiency in Athletes." Journal Nutrition 136 (2): 538S-43S.

[2] Flakoll, P. J., Judy, T., Flinn, K., Carr, C., and Flinn, S. 2004. "Postexercise Protein Supplementation Improves Health and Muscle Soreness during Basic Military Training in Marine Recruits." Journal Applied Physiology 96 (3): 951-6.

[3] Nissen, S., Sharp, R., Ray, M., Rathmacher, J. A., Rice, D., and Fuller Jr, J. C. 1996. "Effect of Leucine Metabolite beta-Hydroxybeta- Methylbutyrate on Muscle Metabolism during Resistance-Exercise Training." Journal Applied Physiology 81 (5): 2095-104.

[4] Twist, C., and Eston, R. 2005. "The Effects of Exercise-Induced Muscle Damage on Maximal Intensity Intermittent Exercise Performance." Euro Journal of Applied Physiology 94 (5-6): 652-8.

[5] Burnley, E. C. D., Olson, A. N., Sharp, R. L., Baier, S. M., and Alekel, D. L. 2010. "Impact of Protein Supplements on Muscle Recovery After Exercise-induced Muscle Soreness." Journal of Exercise Science \& Fitness 8 (2): 89-96.

[6] Sherman, W. M., Armstrong, L. E., Murray, T. M., Hagerman, F. C., Costill, D. L., Staron, R. C., and Ivy, J. L. 1984. "Effect of a 42.2-km Footrace and Subsequent Rest or Exercise on Muscular Strength and Work Capacity." Journal Applied Physiology 57 (6): 1668-73.

[7] Paul, G. L., DeLany, J. P., Snook, J. T., Seifert, J. G., and 


\section{Exercise-Induced Muscle Damage in Trained Athletes}

Kirby, T. E. 1989. "Serum and Urinary Markers of Skeletal Muscle Tissue Damage after Weight Lifting Exercise." Eur. Journal Applied Physiology 58 (3): 786-90.

[8] Chambers, C., Noakes, T. D., Lambert, E. V., and Lambert, M. I. 1998. "Time Course of Recovery of Vertical Jump Height and Heart Rate versus Running Speed after a 90-km Foot Race.” J. Sports Sci. 16 (7): 645-51.

[9] Avela, J., Kyröläinen, H., Komi, P. V., and Rama, D. 1999. "Reduced Reflex Sensitivity Persists Several Days after Long-Lasting Stretch-Shortening Cycle Exercise." Journal Applied Physiology 86 (3): 1292-300.

[10] Horita, T., Komi, P. V., Nicol, C., and Kyröläinen H. 1999. "Effect of Exhausting Stretch-Shortening Cycle Exercise on the Time Course of Mechanical Behavior in the Drop Jump: Possible Role of Muscle Damage.” Eur. Journal Applied Physiology 79 (2): 160-7.

[11] Thompson, D., Nicholas, C. W., and Williams, C. 1999. "Muscular Soreness Following Prolonged Intermittent High-Intensity Shuttle Running." J. Sports Sci. 17 (5): 387-39.

[12] Byrne, C., and Eston, R. 2002. "Maximal Intensity Isometric and Dynamic Exercise Performance Following Eccentric Muscle Actions." J. Sports Sci. 20 (12): 951-9.

[13] Byrne, C., and Eston, R. 2002. "The Effect of Exercise-Induced Muscle Damage on Isometric and Dynamic Knee Extensor Strength and Vertical Jump Performance." J. Sports Sci. 20 (5): 417-25.

[14] Byrne, C., Twist, C., and Eston, R. G. 2004. "Neuromuscular Function Following Exercise-Induced Muscle Damage: Theoretical and Applied Implications." Sports Medicine 34 (1): 49-69.

[15] Warren, G. L., Lowe, D. A., and Armstrong, R. B. 1999. "Measurement Tools Used in the Study of Eccentric Contraction-Induced Injury." Sports Medicine 27 (1): 43-59.

[16] Howatson, G., Hoad, M., Goodall, S., Tallent, J., Bell, G. P., and French, N. D. 2012. "Exercise-Induced Muscle Damage Is Reduced in Resistance-Trained Males by Branched Chain Amino Acids: A Randomized, Double-Blind, Placebo Controlled Study." Journal of the International Society of Sports Nutrition 9 (20): 1-7.

[17] Coombes, J. S., and McNaughton, L. R. 2000. "Effects of Branched-Chain Amino Acid Supplementation on Serum Creatine Kinase and Lactate Dehydrogenase after Prolonged Exercise." Journal of Sports Medicine Physiology Fitness 40 (3): 240-6.

[18] Greer, B. K., Woodard, J. L., White, J. P., Arguello, E. M., and Haymes, E. M. 2007. "Branched-chain Amino acid Supplementation and Indicators of Muscle Damage after
Endurance Exercise." International Journal of Sport Nutrition and Exercise Metabolism 17 (6): 595-60.

[19] Jackman, S. R., Witard, O. C., Jeukendrup, A. E., and Tipton, K. D. 2010. "Branched-chain Amino Acid Ingestion Can Ameliorate Soreness from Eccentric Exercise." Medicine Science Sports Exercise 42 (5): 962-70.

[20] Breen, L., Philip, A., Witard, O. C., Jackman, S. R., Selby, A., and Smith, K. 2011. "The Influence of Carbohydrate-protein co-Ingestion Following Endurance Exercise on Myofibrillar and Mitochondrial Protein Synthesis." J. Physiol. 589 (5): 4011-25.

[21] Nosaka, K., Sacco, P., and Mawatari, K. 2006. "Effects of Amino Acid Supplementation on Muscle Soreness and Damage." Int. Journal Sport Nutrition Exercise Metabolism 16 (6): 620-35.

[22] Shimomura, Y., Inaguma, A., Watanabe, S., Yamamoto, Y., Muramatsu, Y., Bajotto, G., Sato, J., Shimomura, N., Kobayashi, H., and Mawatari, K. 2010. "Branched-chain Amino Acid Supplementation before Squat Exercise and Delayed-onset Muscle Soreness.” International Journal Sport Nutrition Exercise Metabolism 20 (3): 236-44.

[23] Matsumoto, K., Koba, T., Hamada, K., Sakurai, M., Higuchi, T., and Miyata, H. 2009. "Branched-chain Amino Acid Supplementation Increases the Lactate Threshold during an Incremental Exercise Test in Trained Individuals." Journal Nutrition Science Vitaminol. 55 (1): 52-8.

[24] Goodall, S., and Howatson, G. 2008. "The Effects of Multiple Cold-water Immersions on Indices of Muscle Damage." Journal of Sports Science and Medicine 7 (2): 235-41.

[25] Koba, T., Hamada, K., Sakurai, M., Matsumoto, K., Hayase, H., and Imaizumi, K. 2007. "Branched-chain Amino Acids Supplementation Attenuates the Accumulation of Blood Lactate Dehydrogenase during Distance Running." Journal Sports Medicine Physiology Fitness 47 (3): 316-22.

[26] Brown, E. C., DiSilvestro, R. A., Babaknia, A., and Devor, S. T. 2004. "Soy Bars versus Whey Protein Bars: Effects on Exercise Training Impact on Lean Body Mass and Antioxidant Status." Nutr J. 3: 22.

[27] Shenoy, S., Mishra, P., and Sandhu, J. S. 2011. "Peak Torque and IEMG Activity of Quadriceps Femoris Muscle at Three Different Knee Angles in a Collegiate Population." Journal of Exercise Science \& Fitness 9 (1): 40-5.

[28] Bruce, R. A., Kusumi, F., and Hosmer, D. 1973. "Maximal Oxygen Uptake and Normographic Assessment of Functional Aerobic Capacity in Cardiovascular Disease." American Heart Journal 85 (2): 542-6.

[29] Howley, E. T., Bassett, D. R., and Welch, H. G. 1995. "Criteria for Maximal Oxygen Uptake: Review and 


\section{Exercise-Induced Muscle Damage in Trained Athletes}

Commentary." Medicine and Science in Sport and Exercise 27 (9): 1292-301.

[30] Sarabon, N., Panjan, A., Rosker, J., and Fonda, B. 2013. "Functional and Neuromuscular Changes in the Hamstrings after Drop Jumps and Leg Curls.” Journal of Sports Science \& Medicine 12 (3): 431.

[31] Garcia-Tabar, I., Sánchez-Medina, L., Aramendi, J. F., Ruesta, M., Ibañez, J., and Gorostiaga, E. M. 2013. "Heart Rate Variability Thresholds Predict Lactate Thresholds in Professional World-Class Road Cyclists." J. Exerc. Physiol. Online 16: 38-50.

[32] Borsheim, E., Cree, M. G., Tipton, K. D., Elliott, T. A., Aarsland, A., and Wolfe, R. R. 2004. "Effect of Carbohydrate Intake on Net Muscle Protein Synthesis during Recovery from Resistance Exercise." Journal of Applied Physiology 96 (1): 674-8.

[33] Atashak, S., and Baturak, K. 2012. "The Effect of BCAA Supplementation on Serum C-Reactive Protein and Creatine Kinase after Acute Resistance Exercise in Soccer Players.” Annals of Biological Research 3 (3): 1569-76.

[34] Katayama, S., and Mine, Y. 2007. "Antioxidative Activity of Amino Acids on Tissue Oxidative Stress in Human Intestinal Epithelial Cell Model." Journal of Agricultural and Food Chemistry 55 (21): 8458-64.

[35] Wolfe, R. R. 2000. "Protein Supplements and Exercise." Am. Journal Clinical Nutrition 72 (2): 551S-7S.

[36] Shimomura, Y., Kitaura, Y., and Shimomura, N. 2012.
"Effects of Protein and Amino Acid Supplementation on Muscle Protein Metabolism in Relation to Exercise." Journal Physiology Fitness Sports Med. 1 (2): 219-25.

[37] Davies, R. C., Rowlands, A. V., and Eston, R. G. 2009. "Effect of Exercise-induced Muscle Damage on Ventilatory and Perceived Exertion Responses to Moderate and Severe Intensity Cycle Exercise." Eur. Journal Applied Physiology 107 (1): 11-9.

[38] Pyne, D. 1994. "Exercise-induced Muscle Damage and Inflammation: A Review." Aust. Journal Science Medicine Sport 26 (6): 49-58.

[39] Shimomura, Y., Yamamoto, Y., Bajotto, G., Sato, J., Murakami, T., Shimomura, N., Obayashi, H., and Mawatari, K. 2006. "Nutraceutical Effects of Branched-chain Amino Acids on Skeletal Muscle." Journal Nutrition 136 (2): 529S-32S.

[40] da Luz, C. R., Nicastro, H., Zanchi, N. E., Chaves, D. F., and LanchaJr, A. H. 2011. "Potential Therapeutic Effects of Branched-chain Amino Acids Supplementation on Resistance Exercise-based Muscle Damage in Humans." Journal International Society Sports Nutrition 8: 23.

[41] Shimomura, Y., Kobayashi, H., Mawatari, K., Akita, K., Inaguma, A., Watanabe, S., Bajotto, G., and Sato, J. 2009. "Effects of Squat Exercise and Branched-chain Amino Acid Supplementation on Plasma Free Amino Acid Concentrations in Young Women." J. Nutr. Sci. Vitaminol (Tokyo). 55 (2): 288-91. 